\title{
Development of Palm Shell Base Activated Carbon for Volatile Organic Compounds (VOCs) Emissions Absorption
}

\author{
A.M Leman ${ }^{a^{*}}$, M S Muzarpara, Mohd Norhafsam Maghporb, K.A Rahmanc, \\ Nik Normunira Mat Hassanª, Nurasyikin Misdana, Supaat Zakariad \\ ${ }^{a}$ Faculty of Engineering Technolgy, Universiti Tun Hussein Onn Malaysia (UTHM), \\ Pagoh Higher Education Hub, Johor, Malaysia \\ ${ }^{b}$ National Institute of Occupational Safety and Health (NIOSH), Selangor, Malaysia \\ 'Department of Petrochemical Engineering, Politeknik Tun Syed Syed Ismail (PTSN), \\ Pagoh Higher Education Hub, Johor, Malaysia \\ ${ }^{d}$ Department of Mechanical Engineering, Politeknik Ungku Omar (PUO), Perak, Malaysia
}

\begin{abstract}
High concentration of indoor air contaminant commonly released by human activities, furniture, building materials, carpets, cleaning product and paints. BTEX contains Benzene, Toluene, Ethylbenzene and Xylene (BTEX) is categorized into VOCs which are indicative of harmful chemicals especially for indoor air. Therefore, it needs the sampling media for absorption before it could be analyse in the specific laboratory. One of the challenging technology to absorb BTEX is by using Palm Shell Activated Carbon (PSAC). Malaysia has a second largest country that produce palm oil which led to abundant of palm shell as waste material. Activated carbon is created through the carbonization, crushing and activation process. Carbonization process is conducted in various holding time of 1,2 and 3 hours which called by CT1. CT2 and CT3 hours, respectively. Activation process is conducted through physical activation at temperature of $900{ }^{\circ} \mathrm{C}$ for 1 hour, chemical activation is conducted by Potassium Hydroxide $(\mathrm{KOH})$ with ratio of 1:1 (charcoal: chemical) and holding time for 12 hours. It heated by furnace at temperature of $850{ }^{\circ} \mathrm{C}$ for 1 hours in order to improve the porosity and larger surface area. The physical properties were conducted by ASTM 3713, 3714 and 3715 for moisture, as and volatile content measurement. Surface morphology and composition as well as porosity image is characterized by Scanning Electron Microscopy (SEM) coupled by Energy Dispersive Spectroscopy (EDS) machine. The result shows that the lowest ash, moisture and volatile content is shown by CT1 sample, but it has not completely carbonized as compared to CT2 and CT3. Moreover, CT3 has highest ash, moisture and volatile content but it has lowest fixed carbon as compared to CT1 and CT2. Therefore, CT2 hours is selected for further process. In microstructure analysis is observed that the PSAC $\mathrm{physical+chemical}_{\text {has }}$ larger number of porosities with the diameter approximately of 50 to $150 \mu \mathrm{m}$, for $\mathrm{PSAC}_{\text {physical }}$ approximately of 25 to 100 $\mu \mathrm{m}$ and $\mathrm{PSAC}_{\text {chemical }}$ of below than $50 \mu \mathrm{m}$. Composition analysis is observed that the sample is mainly consists of Carbon (C), Oxygen (O) and Potassium (K) content. Where larger porosity is in-line with the increment of $\mathrm{K}$ content which indicated in larger adsorption capacity. It can be summarized that palm

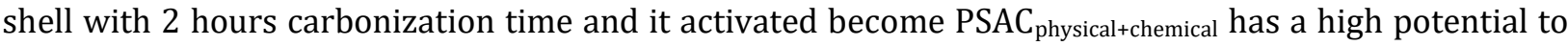
larger adsorption capacity of indoor air contaminant adsorption. It is being further explore for sampling media of BTEX.
\end{abstract}

Keywords: palm shell; activated carbon; VOCs; sorbent tube; material

DOI: $10.37869 /$ ijatec.v2i1.42

Received 12 March 2021; Accepted 11 April 2021; Available online 19 April 2021

(C) The Authors. Published by IRIS. This is an open access article under the CC BY-NC-SA license CC) (i) (2)(2)

\section{Introduction}

Air pollution has emerged as significant environmental issues in the last few decades as a major potential risk to public health, especially in the Southeast Asia region. Rapid economic development coupled with population booming has magnified the air quality issue and therefore the concern of its effect is considered significant. Generally, air pollutants come from both natural and anthropogenic 
source and broadly understood as any material which has grave effect to the environment or detrimental health effect to human and poses the ability to modify the natural characteristic of the atmosphere [1].

The common outdoor air pollutants mainly consist of Carbon Monoxide (CO), Sulphur Dioxide $\left(\mathrm{SO}_{2}\right)$, Nitrogen Oxides $\left(\mathrm{NO}_{\mathrm{x}}\right)$, Ozone $\left(\mathrm{O}_{3}\right)$ and Particulate Matter $(\mathrm{PM})$ with different size $\left(\mathrm{PM}_{10}\right.$ and $\mathrm{PM}_{2.5}$ ) [1]. In Malaysia, these pollutants have been previously characterised by large seasonal variations and generally recognised as local issues which confined to local emission sources, but then have been reported to become a regional issue as pollutants can be transported over a long distance [2].

Several indoor pollutants have been recognized to exist from the outdoor environment including $\mathrm{CO}, \mathrm{SO}_{2}, \mathrm{NO}_{\mathrm{x}}, \mathrm{O}_{3}, \mathrm{PMs}$, while some come from indoor environment itself such volatile organic compounds (VOCs) and hydrocarbon chemicals like benzene, toluene, ethylbenzene and xylene (BTEX). These indoor air pollutants can be exits as biological, inorganic or organic, and even radioactive material which suspended at ambient air. The health effect impinges widely depending on the toxicity, concentration and exposure time. There is less to be argued that the air quality of the outdoor environment can affect mortality and the nation's productivity. However, the issues of indoor air pollution also piqued the interest of many researchers. People tend to spend more time indoors rather than outdoors. Although the variations of time spent vary geographically, seasonally, demographically, good and safe indoor air quality is essential which safeguarding the health and productivity rate of its occupants [3].

Research into the use of palm shell as activated carbon is therefore an important component of filter material to remove hazardous chemicals. As a result of environmental compliance in many countries, demand for activated carbon will continue to rise due to its wide range of uses [4]. Biomass has become one of the main carbon sources for activated carbon production. The biomass used in commercial activities is usually waste materials or by-products. By reusing or recycling these lowcost materials for activated carbon production, we provide another environmentally friendly alternative for waste disposal and by-product disposal [5]. In this study, the palm shell were used as a replacement material of activated carbon in sampling media compared to existing market for chemical exposure monitoring.

\subsection{Background of Study}

The rising trend of transboundary air pollution issues and its associated health impact become the main concern in Malaysia [1], therefore the demand of safe and fresh quality of air is necessary to ensure public wellbeing. Although recent studies have reported that indoor air quality is affected by outdoor air there are also air pollutants originated from an indoor environment which poses carcinogenic health effects and harms its occupants [6]-[7]. According to the World Health Organization report (WHO), approximately 3 billion people around the world exposed significantly to indoor air pollutant mainly through the use of dirty solid fuels for cooking, toxic organic materials from building materials and proximity to the local outdoor air pollutant sources. At this instance, the situation might be getting worse if the house or building had a poor ventilation system which can result in accumulation of indoor air pollutants.

Through the sources and types of indoor air pollutants source are varying, the amount of air pollutants transported in and accumulated within the indoor environment depends on the infiltration and ventilation mechanism. As the overall indoor air quality strongly correlated with both outdoor and indoor environment, mitigation strategy and early action point should be formulated relevance with the indoor and outdoor air pollutants sources. In view of this, the substantial effort needed for a comprehensive understanding of indoor air pollution characterization then followed with the alternative technology in alleviating indoor air pollution.

Regarding to the serious problem caused by indoor air pollutants, porous organic material such as Tenax and styrene polymer like Amberlite XAD-2 have been utilized by researcher to be used as solid sorbent for sampling of volatile organic compound (VOCs) [8]. Tenax is commonly used as general absorbent for the adsorption of non-polar organic compounds. It also highlighted that Tenax are extensively used due to its sensitivity with broad range of boiling point from 60 to $300{ }^{\circ} \mathrm{C}$. And one researche team suggested Amberlite XAD-2 as adsorbent for collection of VOCs [8]. The use of Amberlite XAD-2 was reported to has high surface area and degree of porosity due to its crosslinking 
structure by divinylbenzene (DVB) which enhance the adsorption of the vapours of the solutes. However, there are few disadvantages found from the usage of porous organic material such as Tenax and styrene polymer like Amberlite XAD-2. The formation of artifact in Tenax was observed when it is exposed to very oxidising gases such as ozone, nitrogen dioxide and sulphur dioxide [8]. The example of artifact formed are acetophenone, benzophenone and benzene acetaldehyde. Similar study also revealed that styrene polymer is incompatible to be used as absorbent because of its low maximum desorption temperature. Moreover, the porous organic material was also reported too expensive to be used as general absorbent. Thus, many researchers tend to explore natural resources which is cheaper but efficient as alternative to replace porous organic material.

AC has unique properties including large surface area, a high degree of surface reactivity, universal adsorption effect, and pore size which is extremely effective on removal gases and chemical adsorption. Since indoor air pollution extends beyond health considerations, the objectives of this study are;

i. To study a local material which is a bamboo and palm shell that is commercially available can be used as Activated Carbon.

ii. To produce a volatile organic compound (VOC) sampling media (BTEX) for the equivalent of the chemical monitoring compared to existing market sampling.

AC has unique properties including large surface area, a high degree of surface reactivity, universal adsorption effect, and pore size which is extremely effective on removal gases and chemical adsorption. Since indoor air pollution extends beyond health considerations. There is not much to be argued that the concentration of indoor air contaminants can be higher that outdoor environment. With the increasing concern for better air quality, many researchers have developed various techniques and method that can be implemented to mitigate indoor air pollution issues. In recent years, adsorption in bulk separation technique has emerged as an innovative treatment process suitable for environmental pollution control technology application. Adsorption method provides a low-cost effective and large adsorption capacity can be achieved by increasing the surface area of the adsorbent and the efficiency can be increased by changing the equilibrium and kinetics state of both sorbent and adsorbent [9]. To date, the commercially available activated carbon for the treatment of gaseous pollutants is still limited in this country. Though several adsorption media such as Activated Carbon Fibre (ACF), Silica gel, Zeolite and Alumina exists in the market, the removal efficiency for hazardous air pollutants (such as VOCs and BTEX). The increasing needs toward better environmental air condition have emerged as a considerably most growing concern in recent years. Therefore, a substantial amount of work has been dedicated to developing suitable techniques for mitigation of gaseous pollution and adsorption of gaseous pollutant by AC recognized as one of the most effective preliminary techniques. Based on the statement above, the following are the research questions to be addressed in the study. These questions are as follow:

a) What type of local material (types or species) that most efficient and available that can be used be for sampling media?

b) What are the qualities, parameters and characteristic of the local material that is vital to produce an efficient adsorbent?

c) What is the efficient method to produce volatile organic compound sampling media?

\section{Literature Review}

The ultimate outcome of this research/project is to produce an air filter system which is sustainable, safe and commercially available beside adding commodities value to the waste of bio-resources as well as can act as environmental remediation practic. Bamboo and Palm Oil is a common plant in Malaysia. In 2012 as much 101.96 million tonnes of palm oil fresh fruit bunches (FFB) is processed [10]. More than 5 million palm kernel shells (PKS) produced. Although PKS often used as feeding fuel in a boiler system, it may also be utilized to produce higher-value products such as activated carbons. PKS can be used as a raw material for the production of a range of carbon chars and activated carbons due to its high carbon content. There are many advantages of activated carbon such as high carbon content, high density and low ash content, high absorption capacity, for dissolved organic, chlorine and can be used as the specific application. 
A specific discussion on the volatile organic compounds (VOCS) emissions of palm shell as activated carbon were mentioned in this review to produce an efficient adsorbent. As the second leading oil palm producer after Indonesia, Malaysia is rich with the oil palm plantation throughout the country. To be exact, in 2013, Malaysia had contributed up to 20.2 million metric tonnes of global oil palm production and it increased to 21.25 million metric tonnes in October 2014 [11]. Nevertheless, the rapid expansion in oil palm industry may result in negative consequences towards environment due to accumulation of waste residues [12]. $4 \mathrm{~kg}$ of dried biomass (by-product) will be generated for each $\mathrm{kg}$ of palm oil produced. In addition, it has been reported that only 10 percent of fresh fruit bunch is used for oil production whilst the rest will be discarded as waste materials [13]. The by-products of palm milling process include palm pressed fibre (mesocarp), palm kernel shell (endocarp), and empty fruit bunch (EFB), whilst palm trunk and frond are produced during the harvesting and pruning season [14] - [16]. Currently, solid residues from oil palm processing are disposed through open burning and this contributes to hazardous air pollution problems that affect the neighbouring countries [13]. Therefore, to address this issue, Malaysian's Department of Environment restricts incineration and burning through implementation of the 1978 Environmental Quality Clean Air Regulation Act [17]. Apart from that, solid residues from this sector are occasionally left scattered at the field sites, and consequently, jeopardising the quality of surrounding environment [18]. Improper disposal of oil palm solid waste will contaminate the groundwater through leaching or run-off water, attract air or vector-borne diseases, and give nonaesthetic view. Due to numerous disadvantages of the existing disposal technique, researchers are urged to explore the potential utilisation of the oil palm solid 2 residues [17]

In addition, it has been reported that out of the generated oil palm residues, only 10 percent of them are upgraded into value-added product such as bio-fertiliser [19]. Owing to the high carbon composition, palm wastes are claimed to be advantageous as precursors for the activated carbon production. The literature review revealed that the carbon percentage in palm wastes ranges between $43 \%$ to $47 \%$ while ash only constitute less than 1\% [20]-[22]. From another perspective, conversion of palm wastes may elevate financial income and social status of the surrounding residents through the increased employment opportunities in the cultivation area, especially in rural zones of developing countries. Besides, it will simultaneously promote "greener" oil palm industries [23]. In addition, upgrading oil palm waste to activated carbon is significant due to escalating market demand of this carbonaceous adsorbent to 2.1 metric tonnes by year 2018 [24]. The worldwide demand of the activated carbon in 2012 was approximately 4.28 million metric tonnes and the number is likely to increase at a rate beyond $10 \%$ per annum over the following five years [25]. Meanwhile, market of activated carbon in 2012 was estimated to amount to US\$ 2 billion and is projected to increase to US\$ 4 billion in 2019 [26]. The growing demand of the activated carbon is due to its uniqueness wherein it is applicable in various applications including (i) water purification, (ii) domestic and industrial waste water treatment, (iii) desalination, (iv) gas storage, (v) gas purification and separation, (vi) pollutant and odour removal, (vii) as catalysis support, (viii) and in medical application [27]. Besides, continuous usage of carbonaceous adsorbents is due to its lower price which is $20 \%$ lower than zeolite or polymeric-based adsorbent.

Recently, commercial activated carbon is synthesised from non-renewable precursors: coke, pitch, and coal-based feedstock. The major drawback in utilising these materials is 3 related to their decreasing production trend, and intensive regeneration and reactivation of the commercial activated carbons may contribute to high pricing and result in sorbent degradation. In consequence, the economic feasibility will be affected [28]. Therefore, it justifies the use of oil palm waste as a starting material for activated carbon production. Moreover, utilising oil palm waste is favourable since cultivation area for coconut - one of the common precursors for activated carbon production showed a declining trend; it dropped from 5\% of the total agricultural land in the year 1987 to only $1.4 \%$ in the year 2012. In contrast, palm cultivation area was reported to constitute approximately $64.5 \%$ in the year 2012 as compared to only $25.7 \%$ in the year 1987 [29]. The palm oil fiber $-\mathrm{TiO}_{2}$ ration in the composite on the reduction of BTX and Formaldehyde in the air. The main objective of this paper is to provide an overview of the technological advancement in activated carbon production from oil palm solid waste via conventional heating, microwave heating, or hydrothermal approach. A comprehensive discussion on the activation method via physical and chemical route towards porous activated carbon production is also presented [30]. 


\subsection{Review on Activated Carbon Process}

\subsubsection{Palm Shell as Raw Material for Activated Carbon}

The palm shell were selected for activated carbon preparation. The materials were cleaned with distilled water several times to remove dust and impurities. The palm shell and samples were later dried in the oven at $110^{\circ} \mathrm{C}$ for $24 \mathrm{~h}$ to remove any surface moisture and were then ground to a desired size. The proximate and ultimate analysis were carried out to evaluate the volatiles and fixed carbon contents as well as to quantify the elemental composition, respectively [31]. Palm shell obtained from Malaysia oil palm shell (MOPS) were dried, crushed and sieved to a particle size fraction of $1-2 \mathrm{~mm}$. Potassium carbonate $\left(\mathrm{K}_{2} \mathrm{CO}_{3}\right)$ (purity 99.9\%) was dissolved in distilled water to prepare a saturated solution. An elemental analysis was carried out using a CHNO/S Analyzer 2400. Lignin, cellulose and halocellulose were determined using TAPPI method (T-13wd74, T-17wd-70 and T-9m-54, respectively [32]. Normally the usage of oil palm is $10 \%$ for the oil and the rest $90 \%$ for biomass.

\subsubsection{Preparation of palm shells activated carbon}

Palm shells were mixed with saturated solution $\mathrm{K}_{2} \mathrm{CO}_{3}$ and kneaded. This mixture was then dried in an oven at $110 \mathrm{oc}$ for $24 \mathrm{~h}$ to prepare the impregnated sample. In this work, 0.5, 0.75, 1.0, 1.5 and 2.0 impregnation ratios were used. The impregnation ratio is given by

$$
\text { Impregnation ratio }=\frac{\text { weight of } \mathrm{K}_{2} \mathrm{CO}_{3} \text { in solution }}{\text { weight of palm shell }}
$$

A typical carbonization run began by changing $100 \mathrm{~g}$ of impregnated sample in the reactor and heated up to the carbonization temperature in flowing stream of nitrogen $(151 / \mathrm{min})$. The temperature of reactor was increased at the rate of $10{ }^{\circ} \mathrm{C} / \mathrm{min}$, until it reached the final carbonization temperature. The carbonization temperature was varied from 600 to $1000^{\circ} \mathrm{C}$ with activation duration of $2 \mathrm{~h}$. After carbonization, the sample was cooled down under nitrogen (N2) flow and was washed sequentially several times with hot water, and finally with cold distilled water to remove residual chemicals. Then the sample was dried at $110^{\circ} \mathrm{C}[32]$.

\subsubsection{Physical Activation}

The palm shell were loaded into a stainless steel reactor, which was heated up by an electrical tube furnace. In the initial stage, the reactor was heated up to $300^{\circ} \mathrm{C}$ and was kept at this temperature for 30 minutes. The temperature was later ramped up to about $800^{\circ} \mathrm{C}$. At this rate, Palm shell were completely pyrolyzed. Water was then injected at the flow rate of $120 \mathrm{~mL} / \mathrm{hr}$ to the reactor to activate the samples. The reaction between steam and carbon was taken place and pore was generated. After completing the activation process, the reactor was cool down, the samples was taken out and washed using distilled water [31].

\subsubsection{Chemical Activation}

Palm shell were mixed with $\mathrm{ZnCl}_{2}$ solution with the ratio 1:1 (mass basis) and kept for about $24 \mathrm{~h}$ at room temperature. The samples were then transferred into a stainless steel reactor Nitrogen gas flow of $200 \mathrm{~mL} / \mathrm{min}$ was used for making inert environment inside the reactor and transporting out the volatile compounds. The reactor was heated to $550^{\circ} \mathrm{C}$ and was kept at this temperature for about $1 \mathrm{~h}$. After the activation process was completed, the reactor was cool down and the samples were taken out and washed repeatedly for about 5 times with distilled water to remove access chemical from adsorbents. The list of adsorbent samples prepared in this study is shown in Table 1 [31].

Table 1. List of adsorbent samples prepared

\begin{tabular}{ccc}
\hline Sample & Activating agent concentration (\%) & Yield (\%) \\
\hline Physical activated carbon from PKS (PPAC) & Steam flow 10\% of solid/min for 1h & 22 \\
Chemical activated carbon from PKS (PCAC) & $\mathrm{ZnCl}_{2} 60 \%$ of solid & 44 \\
\hline
\end{tabular}




\subsection{BTEX and Effect to Human Health}

Benzene, toluene, ethylbenzene and xylene (BTEX) are the most common VOCs found in various places and are classified as the air pollutants that hazardous to human [33] - [34]. It is volatile and easy to evaporate at temperature higher than $20^{\circ} \mathrm{C}$. The largest contributors of BTEX to atmospheric was obtained from petrochemical fuel derivatives. Combustion of gasoline and diesel fuels especially for the vehicles contributes to the release of BTEX compound to atmospheric. It is also can be used as intermediates in the synthesis of organic compound for many consumer products. High concentration of BTEX can be retrieved from oil and gas operation [35], automotive industry and storage tank filling [35] -[36] . In addition, municipal waste, traffic, industrial, plastics, solvent extraction and agriculture effluents are the other important source [37]. BTEX compound is well known as the compounds that are harmful to environment and human health though various pathways. The exposure to human especially by direct inhalation may cause adverse effect on human health. The most frequently adverse impacts of BTEX on human health are mainly respiratory irritation and central nervous system damage [38]. Furthermore, the function and development of reproductive system, immune system and metabolic system may be affected if there is long-term exposure. It can be seen by several diseases such as aplastic anaemia and acute myelogenous leukaemia which is caused by benzene, while exposure to ethylbenzene and xylene were also reported can cause acute eye and skin irritation. BTEX are also reported to have significant contribution in formation of oxidants or other air pollutants such as ozone polycyclic aromatic hydrocarbon and ultrafine particles in the atmosphere which may cause serious environmental issues such as haze and ozone depletion [35], [39]. According to Department of Occupational Safety and Health Malaysia, based on Industry Code of Practice 2010, the acceptable limit for total VOCs are $3 \mathrm{ppm}$. Therefore, the method for BTEX removal has gained increasing attention [40].

\section{Methodology}

The methodology clearly describe in order to achieve the objectives of the research study as stated in introduction. Therefore, the good findings and data must be obtained and performed neatly. The main purpose of these project is to determine the efficient adsorbent properties of palm shell as activated carbon. Figure 1 show the flowchart of producing palm shell as activated carbon.

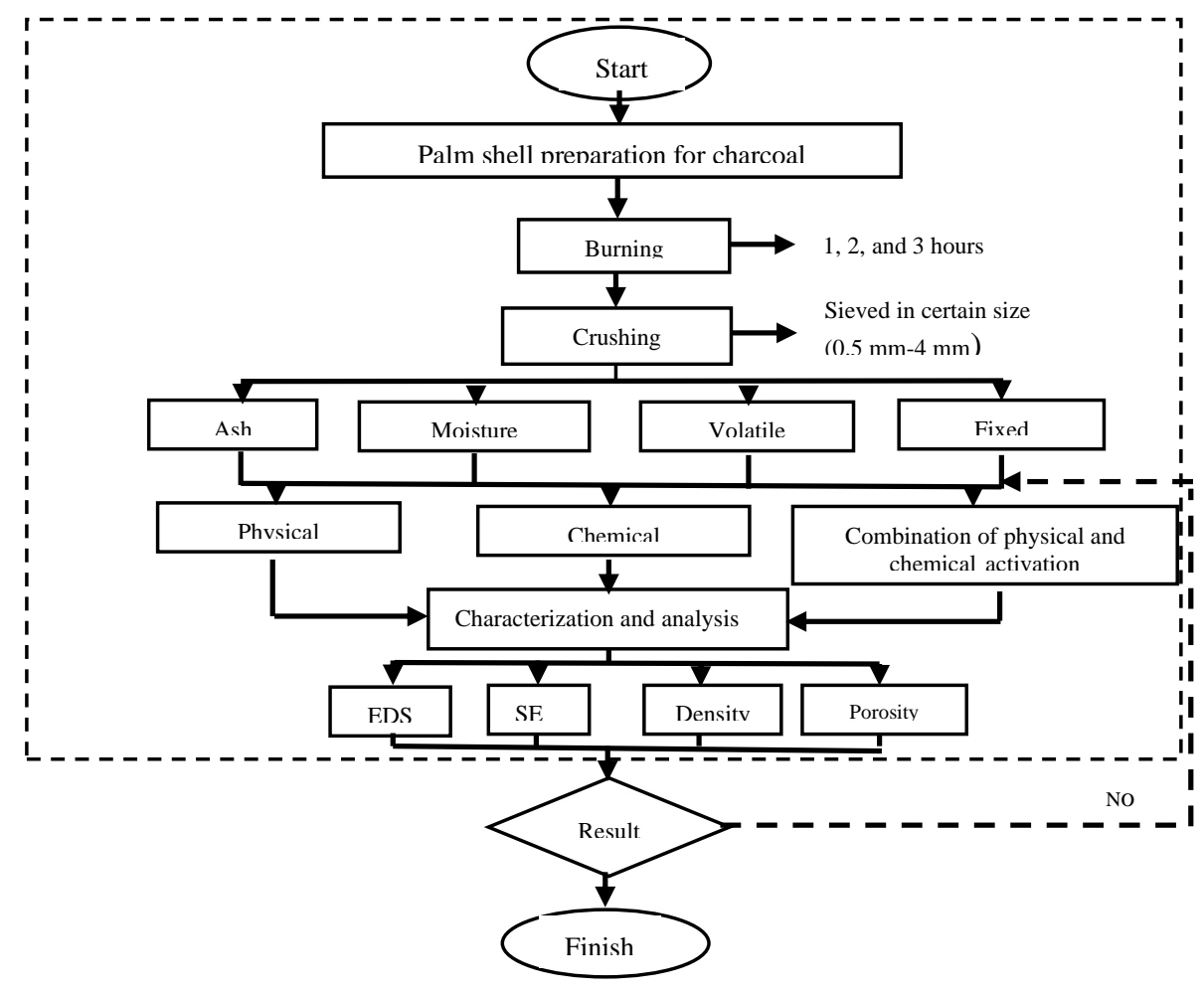

Figure 1. Flow Chart 


\subsection{Collecting Raw Materials}

In this study, the materials used to produce activated carbon are palm shells. The raw materials which are palm shell are collected at nearest Batu Pahat and Pagoh area.

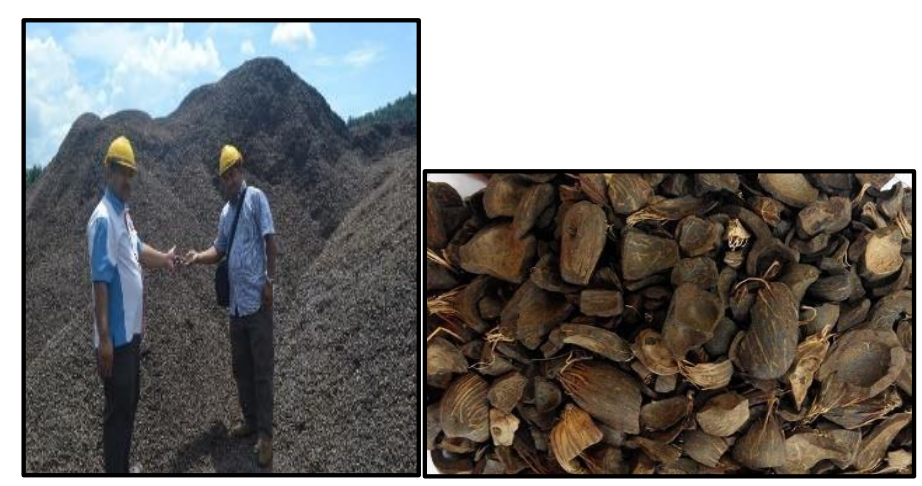

Figure 2. Raw Material of Palm Shell

\subsection{Carbonization Process}

Once the raw materials are free from any dirt, bamboo and palm shell were sun dried to remove excess moisture. The next stage of producing activated carbon is called carbonization process. The formation is black and composed of carbon.

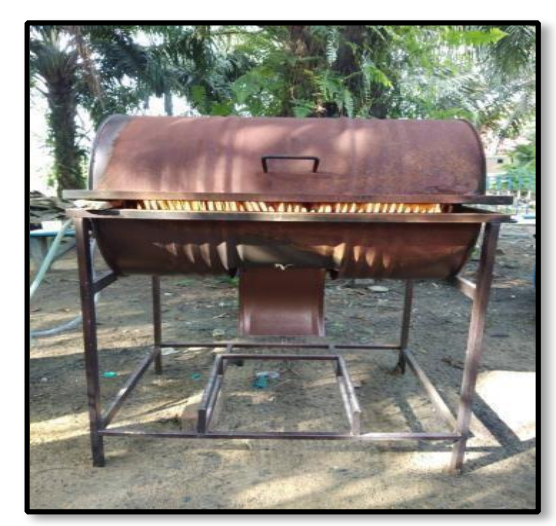

\subsection{Sieving Process}

Figure 3. Carbonization process of raw materials

After the carbonization process, the mixture of bamboo and palm shell were crushing from big sizes into smaller size then ready for sieving process. During this process, the desired product was in powder form. The sample was screened through 50 -micron sieve. The mixture was sieved for several times so that the desired particle carbon sizes was collected.

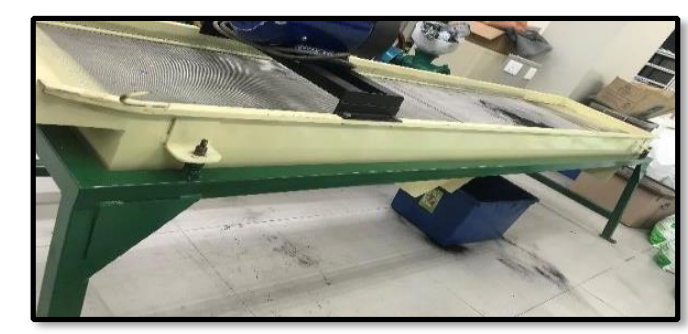

Figure 4. Sieving process of particle carbon

\subsection{Activation Process}

The production of activated carbon will be done by chemical activation process. There were three chemicals will be used which are $\mathrm{KOH}, \mathrm{NaOH}$ and $\mathrm{H}_{3} \mathrm{PO}_{4}$. The composition of the chemicals used to produce activated carbon are based on previous studies that mention in Table 2 . 
Table 2. Composition of chemical to mix with activated carbon.

\begin{tabular}{lll}
\hline Chemical agent & \multicolumn{1}{c}{ Composition } & \multicolumn{1}{c}{ References } \\
\hline $\mathrm{H}_{3} \mathrm{PO}_{4}$ & $85 \%$ & (Arami-Niya et al., 2011) \\
$\mathrm{NaOH}$ & $1000 \mathrm{mg} / \mathrm{L}$ & (Koo et al., 2015) \\
& 10 to $300 \mathrm{mg} / \mathrm{L}$ & (Anirudhan and Sreekumari, 2011) \\
$\mathrm{KOH}$ & $50 \%$ & (Abechi et al.,2013) \\
\hline
\end{tabular}

The samples which are palm shell will be soaked in the chemical mention in above table. The mixtures are then will be dried in an oven [32]. This process is known as impregnation process. Next, it is followed by carbonization and activation process in which the lower temperature will be used. According to the study by Rosas et al (2009), it is reported that the duration of activation for the formation of activated carbon from lingo-cellulosic raw materials using chemical is about 2 hours to ensure all volatile content are removed from the precursor.

\subsection{Cooling and Drying of Activated Carbon}

The samples are allowed to cool down after the chemical activation process, then hot distilled water will be used to wash the sample until the $\mathrm{pH}$ of the washing effluent reach approximately in $\mathrm{pH} 7$ which is neutral. This process is done to ensure the large amount of the pore available for the adsorption as well as ensure the removal and recovery of the chemical used in previous process. The washed product is then dried in an oven and sieve again to obtain the desired size of activated carbon [41].

\section{Testing of Activated Carbon}

\subsection{Testing of activated carbon via Fourier Transform Infrared Spectroscopy (FTIR)}

The characterization of the activated carbon will be done using Agilent Fourier Transform Infrared Spectroscopy (FTIR) to identify the possible functional group such as $-\mathrm{OH}, \mathrm{C}=\mathrm{C}, \mathrm{C}=\mathrm{O}$ and $\mathrm{C}-\mathrm{O}$ groups in the activated carbon which indicates the polarity of the activated carbon that responsible to act as absorbent.The FTIR will be recorded at room temperature with the spectra rang of $500-6000 \mathrm{~cm}^{-1}$.For this activated carbon we found the result in range $500-6000 \mathrm{~cm}^{-1}[42]$.

\subsection{Testing of activated carbon via Scanning Electron Microscopy (SEM) and Energy Dispersive X-Ray Spectroscopy (EDS)}

The sample will be characterized by Scanning Electron Microscopy (SEM) to determine the surface morphology of the activated carbon prepared. The morphology included the distribution of the particles, roughness or smoothness of activated carbon surface, impurities and pore visible on the surface of activated carbon surface. Energy Dispersive X-Ray Spectroscopy (EDS or EDX) will be used for the characterization of the purity of activated carbon. It is done in conjunction with SEM for determination of chemical characteristic of the activated carbon. The EDS characterization is important to determine the adsorption capacity of the activated carbon because increased in purity of carbon will increase in adsorption power of activated carbon [42]. Figure 5 show the microstructure of activated carbon sample.
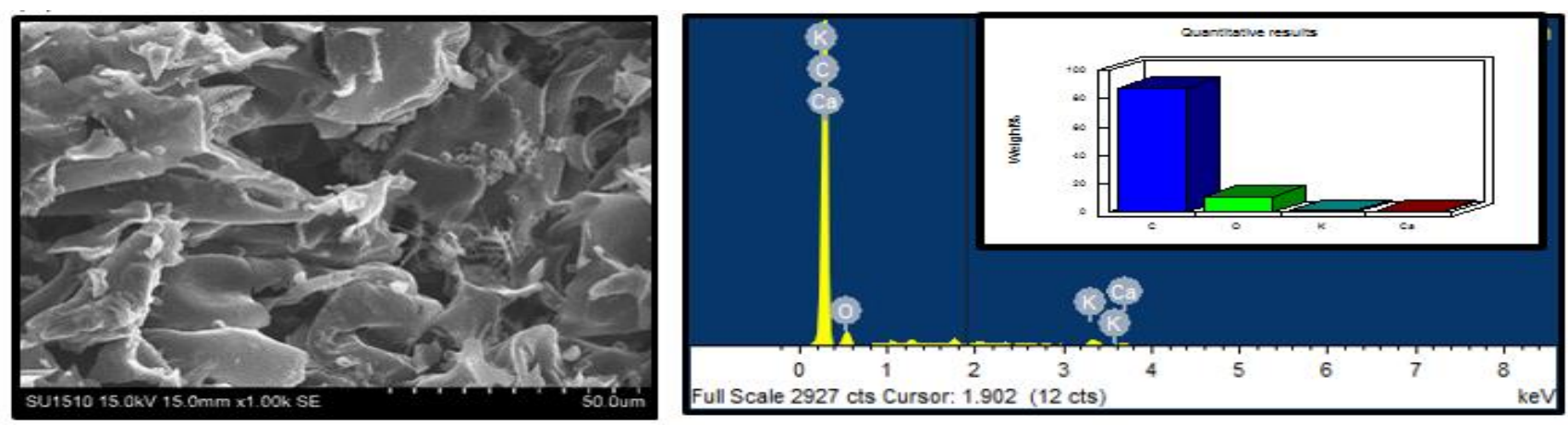

Figure 5. Surface structure and composition analysis of PSAC chemical sample 2. 


\subsection{Preparation of sorbent tube}

The sorbent tube is purchased from local warehouse. The tube will be clean using small metal brush to remove any residue in the tube and make sure it is clean. The tubes will be filled with the activated carbon manually. The weight of activated carbon will be inserted into sorbent tube are in the range of 50-200 milligram. The other end of the tube will be plugged with small plugs of silica wool (5 mm) to hold the material inside the tube. After that, the tubes will be sealed with caps (swage locks). Figure 6 shows the diagram of standard sorbent tube physical appearance [43]. Figure 7 show the physical appearance of the sorbent tube with palm shell activated carbon.

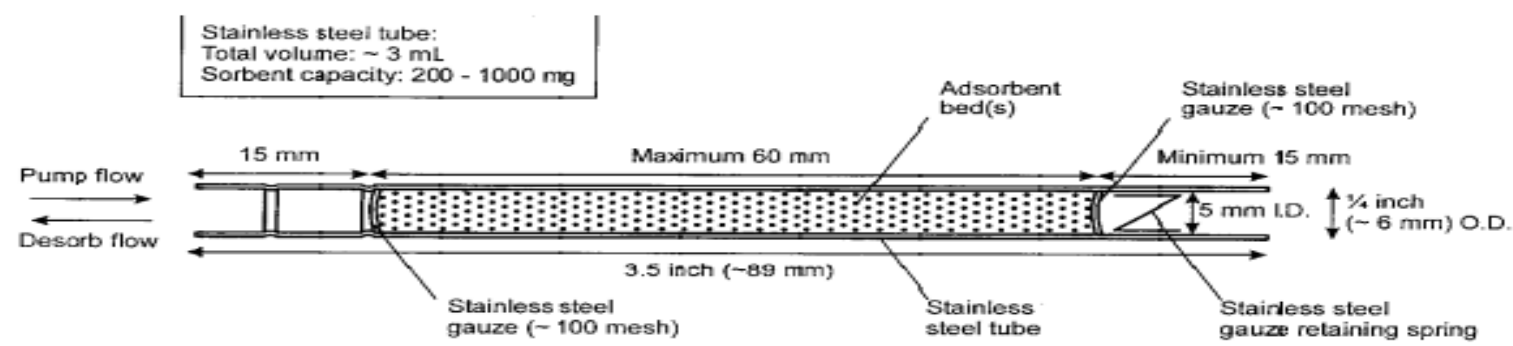

Figure 6. Diagram of standard sorbent tube physical appearance [43]

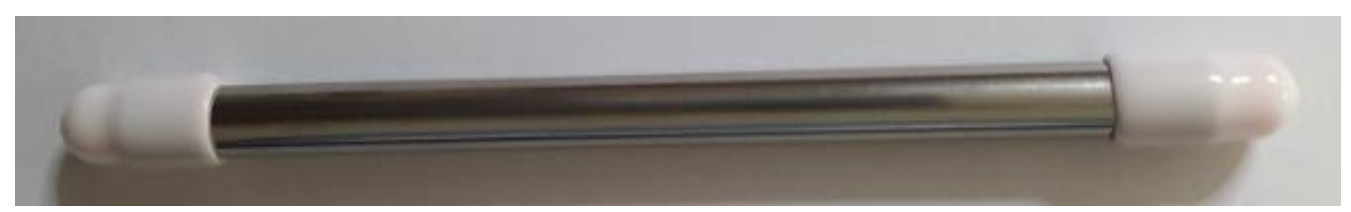

Figure 7. The sorbent tube physical appearance with palm shell activated carbon

\section{Conclusion}

The sorbent tube successfully develops by using palm shell as a sampling media. The sample of CT2 is the best carbonization rather than CT1 and CT3. Therefore, CT2 as a reference of activated carbon for VOCs emissions absorption.

\section{Acknowledgment}

The authors acknowledge the NIOSH Malaysia for the grant funding and UTHM Holdings for the collaboration, the Faculty of Engineering Technology, Universiti Tun Hussein Onn Malaysia for the laboratory and facilities provided throughout these studies. Also great thanks to all members that contribute to this study directly or indirectly.

\section{References}

[1] Sentian, J., Herman, F., Yih, C.Y. and Wui, J.C.H. (2019). Long-term air pollution trend analysis in Malaysia. J. Environ. Impacts. 2 (4). pp 309-324.

[2] Sentian, J., Jemain, M.A., Gabda, D., Franky, H. \& Wui, J.C.H. 2018. Long-term and potential associated sources of particulate matter $\left(\mathrm{PM}_{10}\right)$ pollution in Malaysia. WIT Transaction on Ecology and the Environment. WIT Press. 2018. Vol.230. pp 607-618

[3] Jenkins, P.L., Phillips, T.J., Mulberg, J.M. and Hui, S.P. 1992. Activity patterns of Californias: use of and proximity to indoor pollutant sources. Atmos. Environ. 26: 2141-2148.

[4] Elisabeth s, KLaus t, Christine W, andreas h \& Vander t. 2007. Experiments on the generation of activated carbon from biomass. Journal of Analytical and Applied Pyrolysis 79: 106-111.

[5] Cheong WW., "Preparation and characterization of activated carbons from bamboo for adsorption studies on the removal of surfactants,". M.S thesis, Universiti Teknologi Malaysia, Skudai, 2006.

[6] Meadow, J. F., Altrichter, A. E., Kembel1, S. W., Kline, J., Mhuireach, G., Moriyama, M. (2014). Indoor airborne bacterial communities are influenced by ventilation, occupancy, and outdoor air source. Indoor Air. 24. pp 41-48. 
[7] Fung, C. C., Yang, P., and Zhu, Y. F. 2014. Infiltration of Diesel Exhaust into a Mechanically Ventilated Building. Paper \#HP0626 Indoor Air 2014, Hong Kong

[8] Andrea Marcillo, Viktorija Jakimovska , Anja Widdig, Claudia Birkemeyer. (8 September 2017). Comparison of Two Common Adsorption Materials for Thermal Desorption Gas Chromatography Mass Spectrometry Of Biogenic Volatile Organic Compounds. Journal of Chromatography A Vol.1514. pp 16-28.

[9] Leman, A.M., Zakaria, S., Salleh, M.N.M., Feriyanto, D., Sunar, N.M. and Misdan, N. 2016. Indoor air contaminant adsorption by palm shell activated carbon filter - a proposed study. MATEC Web of Conferences. 78: 01046.

[10] Malaysian Palm Oil Board (MPOB), 2013 Report. MPOB Bangi.

[11] H. Aditiya, W. Chong, T. Mahlia, A. Sebayang, M. Berawi, H. Nur. (2016) Second generation bioethanol potential from selected Malaysia's biodiversity biomasses: A review, Waste Manag. 47. pp 46-61.

[12] Ahmad, A. Buang, A. Bhat. (2016). Renewable and sustainable bioenergy production from microalgal co-cultivationwith palm oil mill effluent (POME): A review, Renew. Sustain. Energy Rev. 65. pp 214-234.

[13] J.C. Kurnia, S.V. Jangam, S. Akhtar, A.P. Sasmito, A.S. Mujumdar. (2016). Advances in biofuel production from oil palm and palm oil processing wastes: A review, Biofuel Res. J. 3. pp 332-346. 27

[14] Y. Uemura, W.N. Omar, T. Tsutsui, S.B. Yusup. (2011). Torrefaction of oil palm wastes, Fuel 90. pp $2585-2591$.

[15] Samiran, M.N.M. Jaafar, C.T. Chong, N. Jo-Han. (2015). A review of palm oil biomass as a feedstock for syngas fuel technology, J. Teknol. 72. pp 13-18.

[16] F. Awalludin, O. Sulaiman, R. Hashim, W.N.A.W. Nadhari. (2015). An overview of the oil palm industry in Malaysia and its waste utilization through thermochemical conversion, specifically vvia liquefaction, Renew. Sustain. Energy Rev. 50. pp 1469-1484.

[17] Singh, M.H. Ibrahim, N. Esa, M. Iliyana,. (2010). Composting of waste from palm oil mill: a sustainable waste management practice, Rev. Environ. Sci. Bio/Technol. 9. pp 331-344.

[18] Shinoj, R. Visvanathan, S. Panigrahi, M. Kochubabu. (2011). Oil palm fiber (OPF) and its composites: A review, Ind. Crop. Prod. 33. pp 7-22.

[19] M. Aslam, P. Shafigh, M.Z. Jumaat. (2016). Oil-palm by-products as lightweight aggregate in concrete mixture: a review, J. Clean. Prod. 126. pp 56-73.

[20] C.Y. Sing, M.S. Aris. (2013). A study of biomass fuel briquettes from oil palm mill residues, Asian J. Sci. Res. 6. pp 537-545.

[21] K.W. Cheah, S. Yusup. (2015) Catalytic pyrolysis of oil palm frond (OPF) using graphite nanofiber (GNF) as catalysts, Chem. Eng. Trans. 45. pp 1543-1548.

[22] K. Doraiselvana, S. Yusup, C.K. Wai, N.S. Muda. (2015). Optimization studies on catalytic pyrolysis of empty fruit bunch (EFB) using L9 Taguchi orthogonal array, Chem. Eng. Trans. 45. pp 1639-1644.

[23] S.H. Shuit, K.T. Tan, K.T. Lee, A. Kamaruddin. (2009). Oil palm biomass as a sustainable energy source: a Malaysian case study, Energy 34. pp 1225-1235.

[24] T. Maneerung, J. Liew, Y. Dai, S. Kawi, C. Chong, C.-H. Wang. (2016). Activated carbon derived from carbon residue from biomass gasification and its application for dye adsorption: Kinetics, isotherms and thermodynamic studies, Bioresour. Technol. 200. pp 350-359.

[25] Saygill, F. Guzel. (2015) High surface area mesoporous activated carbon from tomato processing solid waste by zinc chloride activation: process optimization, characterization and dyes adsorption, J. Clean. Prod. 113. pp 995-1004.

[26] A.E. Eltom, M.P.F. Lessa, M.J. da Silva, J.C. da Rocha. (2012). Production \& characterization of activated carbon membranes, J. Mater. Res. Technol. 1. pp 80-83.

[27] J.M.V. Nabais, C. Laginhas, M.M.L.R. Carrott, P.J.M. Carrott, J.E.C. Amorós, A.V.N. Gisbert. (2013). Surface and porous characterisation of activated carbons made from a novel biomass precursor, the esparto grass, Appl. Surf. Sci. 265. pp 919-924.

[28] V.K. Gupta, B. Gupta, A. Rastogi, S. Agarwal, A. Nayak, Pesticides removal from waste water by activated carbon prepared from waste rubber tire, Water Res. 45 (2011) 4047-4055.

[29] J. Othman, Y. Jafari. (2014) Selected research issues in the Malaysian agricultural sector, J. Ekon. Malays. 48. pp 127-136.

[30] Nor Rahaiza Abdul Manap, Roslinda Shamsuddin, Mohd Norhafsam Maghpor, Muhammad Azmi Abdul Hamid and Azman Jalar. (2016) Effect of Palm Oil Fiber -Tio 2 Ration in the Composite on the 
Reduction of BTX and Formaldehyde in the Air. Malaysian Journal on Analytical Sciences. 20 (2). pp 324-328.

[31] Hidayu, A. R., \& Muda,N.(2016). Preparation and Characterization of Impregnated Activated Carbon from Palm Kernel Shell and Coconut Shell for $\mathrm{CO}_{2}$ Capture. Procedia Engineering, 148. pp 106-113.

[32] Adinata,D.,Wandaud,W.,\& Aroua,M.(2007). Preparation and characterization of activated carbon from palm shell by chemical activation with K2CO3. Bioresource Technology, 98(1). pp 145-149

[33] Ertan Durmusoglu, Fatih Taspinar, Aykan Karademir. (2010). Health risk assessment of BTEX emissions in the landfill environment. Journal of Hazardous Materials 176. pp 870-877

[34] Nor Rahafza Abdul Manap, Roslinda Shamsuddin, Mohd Norhafsam Maghpor, Muhammad Azmi Abdul Hamid and Azman Jalar (2018). Adsoprtion Isotherm and Kinetic Study of Gas-Solid System of Formaldehyde 0n Oil Palm Mesocarp Bio-Char: Pyrolysis Effect. Journal of Environmental Chemical Engineering 6. pp 970-983.

[35] Latif, M.T., Abd Hamid, H.H., Ahamad, F., Khan, M.F., Mohd Nadzir, M.S., Othman, M., Sahani, M., Abdul Wahab, M.I., Mohamad, N., Uning, R., Poh, S.C., Fadzil, M.F., Sentian, J., Tahir, N.M., BTEX compositions and its potential health impacts in Malaysia, Chemosphere. (2019).

[36] Ashley L. Bolden, Carol F. Kwiatkowski, and Theo Colborn. (2015). New Look at BTEX: Are Ambient Levels a Problem? The Endocrine Disruption Exchange (TEDX), Paonia, Colorado 81428, United States, Department of Integrative Physiology, University of Colorado Boulder, Boulder, Colorado 80309, United States

[37] Mingkwan Kitwattanavong, Tassanee Prueksasit, Daisy Morknoy, Tanasorn Tunsaringkarn \& Wattasit Siriwong (2013) Health Risk Assessment of Petrol Station Workers in the Inner City of Bangkok, Thailand, to the Exposure to BTEX and Carbonyl Compounds by Inhalation, Human and Ecological Risk Assessment: An International Journal, 19 (6). pp 1424-1439.

[38] A.A.M. Daifullah, B.S. Girgis. (2003). Impact of surface characteristics of activated carbon on adsorption of BTEX. Colloids and Surfaces A: Physicochem. Eng. Aspects 214 (2003) 181193

[39] Yujie Zhang, Yujing Mu, Junfeng Liu, Abdelwahid Mellouki. (2012). Levels, sources and health risks of carbonyls and BTEX in the ambient air of Beijing, China. Journal of Environmental Sciences, 24(1). pp 124-130.

[40] Juping You, Mine Du, Han Chen, Xinying Zhang, Shihan Zhang, Jianmeng Chen, Zhuowei Cheng, Dongzhi Chen, Jiexu Ye. (2018). BTEX degradation by a newly isolated bacterium:

[41] Department of Occupational Safety and Helath 2010. Code of Practice on Indoor Air Quality (IAQ). Ministry of Human Resources Malaysia. Putrajaya.

[42] Valix, W.H. Cheung, G. McKay, Preparation of activated carbon using low temperature carbonisation and physical activation of high ash raw bagasse for acid dye adsorption, Chemosphere 56 (5) (2004). pp 493-501.

[43] Jeanne Rampe, VistaraniArini Tiwow, "Fabrication and characterization of activated carbon from charcoal coconut shell minahasa, Indonesia" $2^{\text {nd }}$ International Conference on Statistics, Mathematics, Teaching, and Research IOP Publishing IOP Conf. Series: Journal of Physics: Conf. Series 1028 (2018) 012033.

[44] Elizabeth Woolfenden (1997) Monitoring VOCs in Air Using Sorbent Tubes Followed by Thermal Desorption-Capillary GC Analysis: Summary of Data and Practical Guidelines, Journal of the Air \& Waste Management Association, 47(1). pp 20-36. 